\title{
El caballero pragmático: Richard Rorty o el liberalismo con rostro humano
}

\author{
RAFAEL DEL ÁGUILA \\ Universidad Autónoma de Madrid
}

Este trabajo trata de ofrecer una panorámica de la obra de Richard Rorty con especial referencia a alguno de los problemas políticos que se deducen de sus tesis: la apuesta por la contingencia, la división privado/público, el cosmopolitismo y la emancipación, el etnocentrismo, etc.

[...] ¿ves all, amigo Sancho Panza, donde se descubren treinta, o pocos mâs, desaforados gigantes, con quien pienso hacer batalla? [...]

-Mire vuestra merced - respondió Sancho- que aquellos que allí se parecen no son gigantes, sino molinos de viento [...]

M. DE CERvantes: El ingenioso hidalgo Don Quijote de la Mancha, I, 8

\section{Introduccion}

El caballero de la triste figura atacaba lanza en ristre vistosos molinos de viento que él tomaba por gigantes. El caballero pragmático, en cambio, se abalanza sobre lo que todo el mundo ha tomado por gigantes con la convicción de estar agrediendo modestos molinos. No se trata, sin embargo, de una simple inversión. Tampoco de que el aspecto y la orientación del caballero pragmático sean las de Sancho Panza. Algo de eso hay, desde luego. Algo en él recuerda el sentido común y la razonabilidad a flor de tierra del escudero. Pero también es verdad que este caballero inicia la justa con un espíritu en cierta medida quijotesco. También él quiere, como Don Ouijote, liberarnos de algo: de las malas autodescripciones, de las excesivas pretensiones de la racionalidad, de la desmesura de la emancipación, de la metafísica de la verdad, etc. A cambio, obtendremos cosas pequeñas, ligeras, casi imperceptibles, pero fundamentales para nosotros: la democracia realmente existente, el sentido común, el reformismo político, una esfera privada en la que practicar las actividades sublimes que deseemos, la pluralidad de opiniones bien justificadas, etc. Si el impulso es quijotesco, el resultado puede parecer más próximo a Sancho Panza. Aunque quizá esto sólo sea aparente y la relación sea algo más compleja. 
Hay quien opina que Richard Rorty ha sido una especie de espina en el costado del establishment académico, y que se las ha arreglado para desconcertar y provocar a diestro y siniestro: a la filosofía analítica angloamericana, a la filosofia especulativa continental, a los postmodernos, a la derecha, a la izquierda, y, en general, a casi todo el mundo.

No es para menos, desde luego, porque ese filósofo se muestra decididamente en contra de la teoría (lo que, según L.S. Klepp, sería como ser banquero y estar contra el dinero); reivindica el triunfo de la poesía y de la literatura sobre la filosofía en artículos académicos convencionales y generalmente muy bien escritos; se constituye como una vocecilla irreverente (la vocecilla de la contingencia) capaz de sacar de quicio a voces quizá mejor moduladas (Rawls, Habermas, MacIntyre), pero no más incisivas; pretende no pagar el precio tradicional de la verdad, la justicia o la racionalidad (esto es, fundamentación y certeza), pero, al mismo tiempo, espera poder disfrutar de algunas de sus principales ventajas (esto es, libertad, solidaridad, democracia); quiere reinterpretar a los críticos de la modernidad (Nietzsche, Heidegger, Foucault, Derrida) y usarlos en la paradójica tarea de hacer más profunda nuestra autonomía y nuestra autocreación en la esfera privada; etc. Lo menos que podría decirse de un programa reflexivo semejante es que es original. El máximo elogío que se le podría dedicar es que ha puesto en marcha nuevas maneras de pensar(nos) y que ha impulsado en nosotros redescripciones fructíferas.

Richard Rorty nació en 1931. Dos años después su padre, James Rorty, rompía con los comunistas y empezaba a trabajar, junto con Sidney Hook, en el frente anti-estalinista trotskista. $\mathrm{Al}$ caballero pragmático le parece, acaso no sin razón, que gran parte de esa izquierda de los treinta era básicamente liberal. Así pues, no ve en su posición actual ruptura alguna con su ambiente y sí la esencial continuidad de su propia tarea en el seno de una tradición familiar.

Nuestro filósofo fue un muchacho solitario y que leía libros tan ávidamente como Alonso Quijano. Creció en un ambiente en el cual, haciendo de correo entre la Liga de Defensa de los Trabajadores (donde sus padres trabajaban) y Norman Thomas (candidato a la Presidencia de EE.UU. por el Partido Socialista), y husmeando en los papeles que transportaba, llegó a creer que toda la gente decente del mundo era, si no trotskista, al menos socialista. Según confesión propia, a los doce años estaba convencido de que ser una persona significaba dedicar la vida a la lucha contra la injusticia social. Pero junto con su interés por la política, pronto empezó a desarrollarse un mundo privado, incomunicable y una pizca esnob alrededor de las espléndidas orquídcas salvajes que crecían en las montañas de Nueva Jersey. Su confesada obsesión desde entonces fue reconciliar ambas esferas y lograr ser, a un tiempo, "un intelectual esnob" y "un amigo de la humanidad». Su arriesgada división entre lo público y lo privado, de 
la que luego hablaremos, supone de hecho el fin de un programa reflexivo en el que la reconciliación era el centro de interés y su sustitución por una estrategia de separación de las dos esferas que pueda hacer justicia a ambas.

A los quince años escapó de sus bárbaros compañeros de clase, que le golpeaban regularmente en el patio de la escuela, e ingresó en la Universidad de Chicago. Tras un año de intentos frustrados, decidió dejar de escribir poesía y abandonar la literatura por la filosofía. Pese a que su conexión pragmática había sido ya establecida (Sidney Hook, el amigo de su padre, era el heredero de John Dewey en la Universidad de Columbia), decidió aceptar una oferta de Princeton, por aquel entonces dominada por la filosofía analítica.

En los sesenta, tras editar The Linguistic Tum, atraviesa una crisis personal y profesional quc lc impide escribir. Durante ese periodo redescubre a Dewey, Whitman y la cultura americana en general, y comienza propiamente a existir el caballero pragmático que conocemos. Así por ejemplo, paulatinamente empezó a ver las polémicas sobre el giro lingüístico y su relación con la filosofía, no como uno de los más importantes acontecimientos de la historia de la filosofía, sino como una tempestad en un vaso de agua académico (véase Rorty, 1992b, 371). Esa transformación teórica y algunas de sus consecuencias prácticas le permitieron experimentar cómo el furor de los filósofos analíticos podía llegar a ser muy real. Desde luego, en nada mejoró su situación a ese respecto la publicación en 1979 de su libro Philosophy and the Mirror of Nature.

Desde 1983 no pertenece ya a un Departamento de Filosofía, sino que es Professor of Humanities en la Universidad de Virginia, Charlottesville. Vive en una rústica casa, a unos quince kilómetros de su lugar de trabajo, con su porche, su chimenea de piedra y sus montañas al fondo. Su coche, un Volvo, tiene una matrícula que comienza con las siglas PRAG. Es una celebridad, su trabajo es reconocido en todo el mundo, y es, sin duda, una estrella del panorama filosófico. Sin embargo, una pegatina adherida a su coche reza: «I'd rather be birding», y probablemente es cierto. Después de todo, la búsqueda de lo sublime puede resultar bastante más gratificante que la limitada y un tanto aburrida ingeniería política reformista.

\section{Verdad, opinión y giro etnocéntrico}

La posición teórica que Rorty adopta es inseparable de la crisis que se ha producido tanto en la filosofia como en la política en los últimos veinte años. De las diversas etiquetas con las que contamos para describir esta situación contemporánea quizá la más adecuada, por resultar la más general, sea la de crisis de la modernidad. Tras el ataque concertado contra ciertos fundamentos de la modernidad hasta entonces casi incontroverti- 
bles, parece que la filosofía ya no es lo que era. Aunque quizá, parafraseando lo que Robert Graves hace decir a uno de sus personajes sobre la crisis del teatro en la Roma de Augusto, puede ser que la filosofía nunca fue lo que era. Ésa es, al menos, la posición del propio Rorty.

Aunque parezca que nos encontramos ante una crisis de enormes dimensiones, profunda y decisiva para nuestra cultura filosofica, moral y política, y que los puntos de referencia a través de los cuales solíamos pensar y/o orientar nuestras acciones han desaparecido bruscamente ante nuestros ojos, lo cierto es que resulta exagerado interpretar esta situación como una crisis fundamental para nuestra cultura. A lo que estamos asistiendo es a un suceso lateral, sin duda importante, pero que está lejos de ser decisivo. Lo que hemos perdido, the world well lost (1982, 3 ss.), no es más que una cierta tradición del pensamiento occidental: la de la fundamentación de la racionalidad. Descartes, Locke, Kant, Hegel o, en otro sentido, Marx o el primer Wittgenstein, serían algunos de sus puntos de referencia. Nietzsche o Dewey o Heiddeger o Derrida alguno de sus enteradores.

Ahora bien, en vez de lamentar que las ideas metafísico-fundacionales se estén desvaneciendo, Rorty propone, desde un primer momento, una variación de nuestra actitud ante esta crisis. No se trataría de recomponer la situación en nuevos términos (como los intentos de Rawls o Habermas, por ejemplo, prescribirían), ni tampoco de dar por sentada la desaparición de ideas y valores asociados a aquella fundamentación y que nos son todavía queridas (como ciertas páginas de Foucault o Lyotard, por ejemplo, podrian hacer pensar). A este respecto, nuestra tarea es doble. Por un lado, hay que desembarazarse de lo que Bernstein llamó «ansiedad cartesiana" (1983, 16 ss.), esto es, de la búsqueda de fundamentos incontrovertibles y racionales para nuestro pensar y de seguridad en nuestro actuar moral y político. Por otro lado, hemos de reivindicar todo un conjunto de valores y creencias que nacieron asociadas, en buena parte, a aquella tradición, pero que son todavía esenciales para nuestra forma de vida (libertad, democracia, igualdad, solidaridad, etc.). Aunque estos valores y creencias estuvieron en un tiempo conectados fuertemente con ideas como certeza y seguridad, a Rorty le parece que son perfectamente reivindicables dentro de una alternativa dispuesta a manejarse en el seno de la contingencia y el "pensamiento débil" (Vattimo y Rovatti, 1983).

En esta línea, Rorty identifica el deseo de constricción que la búsqueda de principios fundamentadores revela, con la tradición que, hundiendo sus raices en Platón, Descartes y otros, afimma que la verdad es un reflejo de una "objetividad exterior". Se supone que, gracias a la sagaz disposición de ese espejo interior que poseemos, se nos permitiría acceder a la realidad y "ver" con claridad lo que de todas formas "está ahí fuera», Precisamente esta teoría de la verdad como reflejo estaría en la base de 
gran parte de los malentendidos y paradojas con que nos enfrentamos (1983a, 121 ss., 304 ss., etc). De hecho, para empezar a pensar en términos más fructíferos en este punto, deberíamos estar dispuestos a abandonar la diferencia entre verdad y opinión. Hasta el momento, el primero de estos conceptos ha venido identificándose con la idea de correspondencia con la realidad exterior, mientras el segundo hacía referencia a creencias más o menos arbitrarias y no elaboradas. Pero la alternativa es falsa. De hecho, si abandonamos la teoría de la verdad como reflejo, lo que tenemos al otro extremo es la idea de verdad entendida como creencia bien (o suficientemente) justificada (1991b, $21 \mathrm{ss}$.).

Ahora bien, lo que parece preocupar de esta operación es que junto con el fundarnento seguro y cierto se desvanece la idea de razón, al menos tal y como ha sido mayoritariamente entendida hasta ahora. Muy cerca de ese miedo aguarda la sensación de que el filósofo ya no puede ser más «el guardián de una racionalidad» que, propiamente, no existe en esos términos. Pero ésta es otra idea de la modemidad que conviene ir dejando de lado, ya que confunde el papel social del intelectual y le hace funcionar como una especie de supervisor cultural, en lugar de mantenerle en la más adecuada y modesta tarea de intermediario socrático entre discursos (1983a, 289 ss., etc.).

Es en este contexto donde Rorty introduce su idea de que quizá lo que deberíamos perseguir sería la creación de una «filosofía edificanten en la que el interés en mantener la conversación entre los participantes en el diálogo desplazara al tradicional objetivo de descubrir la verdad. En sus propios términos, se trataría de una apuesta por la solidaridad que sustituiría a un respeto inconsecuente por la objetividad o a una actitud de adoración del hecho (1983a, 323 ss., etc.). Su pragmatismo, de este modo, defendería valores conversacionales, la voluntad de hablar y escuchar, las virtudes socráticas, etc. Y este desplazamiento tendría consecuencias extremadamente importantes.

Bien es cierto que esta opción valorativa no puede ser apoyada, y él lo sabe, en una teoría fundamentada de la racionalidad. En este aspecto es inútil intentar «salir de nuestra propia piel» e ir más allá de lo que son nuestras tradiciones y valores (1982, XIX). Pero, por eso mismo, la apuesta por la solidaridad lo es también por el mantenimiento y consecución de ciertos estilos de vida: los de la cultura occidental.

Dicho de otro modo. Por un lado, ya no tenemos ningún "confort metafísico", como lo llamó Nietzsche, que nos permita manejarnos en estas cuestiones con la certeza y la seguridad de la objetividad. Abandonada esta esperanza, la opción conversacional, dialógica y solidaria no es más que nuestra manera de ver las cosas, sin que pueda pretender universalidad alguna. Después de todo, ésta es una opción por ciertas virtudes éticas: la civilidad, nos dice Rorty, es simplemente una virtud $(1983 b, 169)$. 
Ahora bien, si la conversación, la justificación, la argumentación, etc., no son más que virtudes o, más apropiadamente, nuestra forma de ver las cosas, ¿no sería de desear que este entramado dialógico, que aspira a sustituir, entre otras cosas, a la teoría de la verdad como correspondencia de la epistemología, describiera su funcionamiento interno? Dicho de otro modo, ¿no sería necesario estipular una serie de reglas y considerarlas como presupuestos de toda conversación?

En efecto, dice nuestro autor, pero esos criterios sólo deben entenderse como lugares de acuerdo temporal y contingente (temporary resting places) construidos para fines específicamente utilitarios y sujetos a rescisión. De hecho, nuestra única guía en la conversación son los compañeros de nuestra comunidad, es a ellos a los que debemos lealtad y es con ellos con los que acordamos realmente y no con comunidades imaginarias representantes de la verdad o la justicia en términos "supracomunitarios» (1982, 172). Es nuestra comunidad occidental la que guía y corrige nuestras pretensiones $\mathrm{e}$ inclusa la idea de que es bueno, provechoso o reflexivamente fructífero regirse por un sistema conversacional es únicamente nuestra idea de las cosas, sin que exista a ese respecto ninguna garantía particular de éxito.

La teoría rortyana abandona así definitivamente sus puntos de conexión con intentos en cierta medida similares de Rawls o Habermas. Siendo estos últimos partidarios del establecimiento de una serie de reglas de racionalidad dialógica universalizables, se les ha reprochado, quizá no sin razón, que los presupuestos por ellos descritos como universales no son más que una hipóstasis de valores culturales de nuestra comunidad. ${ }^{2}$

Pero salir de un problema es siempre entrar en otro. Si el caballero pragmático puede ahorrarse las discusiones sobre universalización de reglas de procedimiento de la conversación, no puede, en cambio, eludir una respuesta sobre la multitud de preguntas que surgen de este giro etnocéntrico (nuestra comunidad, nuestros valores como fundamento único de saber y acción), ni muchos de sus problemas internos.

\section{Contingencia}

La crisis de la modernidad ha tenido, pues, una consecuencia inmediata que debemos asumir: ya no existe para nosotros la posibilidad de reivindicar un fundamento incontrovertible para nuestra racionalidad, ni para nuestros proyectos de acción práctica. La contingencia, en el sentido más profundo y extenso de la expresión, es lo único que nos rodea. El caballero pragmático nos propone ahora, tras derrotar a los molinos que tomamos por gigantes, que adoptemos el punto de vista del escudero Sancho y abandonemos el terreno de la añoranza de la metafísica tradicional. La descripción de la contingencia debe perder sus tonos trágicos y adoptar la razonabilidad del sentido común. 
Existen tres vectores principales a través de los cuales la contingencia se nos revela: el yo, ${ }^{3}$ el lenguaje y nuestra comunidad liberal (1989, parte I).

Autores como Freud y Nietzsche nos ayudan a entender que es la "huella ciega» (blind impress) de la contingencia la que determina nuestro yo y su esencial historicidad. Unicamente las distintas maneras de tejer y destejer historias sobre esa huella es lo que nos conforma. Somos nada más que el proceso de redescripción continua sobre el conjunto de procesos y experiencias contingentes y particulares, una red de deseos y creencias en continua evolución. Nuestro problema no es lograr la descripción justa de nuestro yo entendido como una sustancia que está "ahí» esperando ser desenterrada. Nuestro problema es la apertura continua a descripciones altemativas. Así las cosas, la exigencia de redescripción se hace todavía más acuciante puesto que, como ya Nietzsche señalo, fracasar como "poeta" de la autodescripción es fracasar como ser humano, pues significa conformarse con las descripciones que otros hacen sobre uno mismo. En esta visión de las cosas, las metáforas de creación han desplazado a las metáforas del descubrimiento típicas de la metafísica y el yo aparece como producto y no como esencia descubierta.

Del mismo modo debemos asumir la historicidad radical de nuestros vocabularios alternativos y abandonar la esperanza de poder juzgar de acuerdo con un tribunal "más alto" su adecuación, su justicia o su verdad. Si ya Wittgenstein o Heidegger trataron de formular unos términos honrosos para la rendición de la filosofía ante la poesía, el reconocimiento de este hecho nos obliga a sustituir la figura del "teórico" que fundamenta en la razón, por el "poeta fuerte» de la redescripción. Ello implica, y la implicación es desde luego "fuerte", que no existe manera de diferenciar racionalmente entre el contenido de verdad o de justicia de la pluralidad de descripciones alternativas. Los distintos vocabularios tienen a este respecto un poder extremadamente alto: "cualquier cosa puede hacerse aparecer como buena o mala a través de la redescripción» (1989, 73). Así, tales vocabularios no son más que herramientas alternativas que constituyen distintos proyectos de conocimiento y no formas diferentes de acceso a lo real. La verdad aquí no es más que, de nuevo en expresión nietzscheana, "un ejército de metáforas móviles" $(1989,11-13)$. O, si se prefiere la frase de William James, lo que nos resulta conveniente creer (what is good for us to believe) (1991b, I, 22).

Ahora bien, la contingencia del yo unida a la contingencia del lenguaje ¿no nos entrega a la más absoluta arbitrariedad que suele acompañar al relativismo? Y en ese caso, nuestros valores más queridos (libertad, democracia, etc.) ¿no se ven amenazados por sus contrarios (opresión, totalitarismo, etc.)? ¿Ambos ejes de contingencia no nos abocan a una contingencia de nuestra comunidad acaso mayor de la que estamos dispuestos a admitir? 
Aquí sigue funcionando en el caballero pragmático la razonabilidad de Sancho: las instituciones de la democracia liberal serán mejor servidas por un vocabulario débil que evite distinciones como racional-irracional, moralidad-prudencia, relativismo-absolutismo, que por un vocabulario como el procedente de la modemidad. Este se ha convertido ya en un impedimento (pese a ser lo contrario en sus inicios) para la preservación y el progreso de las democracias. De hecho, si algo hay de bueno en la democracia liberal, fue conseguido por una suma de procesos contingentes, a través de luchas y sufrimientos $(1982,168)$, y no por la existencia o no de una Razón o una Marcha de la Historia (con mayúsculas). Nuestra comunidad liberal democrática no requiere que escapemos al reconocimiento de su contingencia a través de fundamentación alguna, sino que exige con urgencia autodescripciones mejoradas. En este sentido, esas autodescripciones deben dirigirse hacia una poetización de la cultura, más que a su racionalización. $Y$ esto aunque tal posición signifique que no podemos demostrar incontrovertiblemente que nuestra forma de vida democrática es superior a, digamos, el totalitarismo comunista o fascista o al fundamentalismo islámico. Después de todo no tenemos manera de silenciar nuestras dudas sobre esta elección como no la tenemos de "asegurarnos" la amistad o el amor $(1989,52-54)$. Y pese a todo, insiste Rorty, este posicionamiento no implica ni relativismo ni quietismo. En buena parte, la lección del caballero pragmático (que aquí vuelve a coquetear con Don Quijote y a abalanzarse sobre los molinos), es que una mera creencia puede considerarse como una profunda regla de acción práctica, aun cuando sepamos que no ha sido creada por nada más fundamental que «circunstancias históricas contingentes» $(1989,189)$.

Sin embargo, el Sancho razonable y el Quijote luchador se han entremezclado hasta ahora de forma tan confusa, que muchos de los problemas que todavia laten en las prescripciones del caballero pragmático parecen proceder de ésa su doble cara. La propuesta rortyana es, aquí como en otros lugares, extremadamente fuerte: se trata de encerrar las actividades de uno y otro en compartimentos estancos, de modo que ninguno pueda interferir demasiado en las actividades del otro. Se trata de encerrar a Don Quijote en el mundo de lo privado y de confinar a Sancho en el reino de lo público.

\section{Lo privado y lo público}

En línea con algo así como un postmodernismo liberal, Rorly propone una taxativa división entre lo privado y lo público, Las demandas de autocreación, de transformación, de lo sublime, de la perfección, pertenecen a la esfera privada. Las demandas relativas a la solidaridad, reciprocidad, responsabilidad, eliminación de la crueldad y de la humillación, pertenecen a 
la esfera pública. Ambos tipos de demandas y proyectos son igualmente válidas, pero inconmensurables (1989, xv). Dicho en términos biográficos: no hay forma de tejer una historia coherente capaz de integrar a Trostky y a las orquídeas salvajes. Dicho con palabras de Richard J. Bernstein, la solución a la tensión entre ironía privada y esperanza social es el apartheid (1992a).

Cada una de estas esferas es el campo de acción de una personalidad distinta. En la esfera privada, la ironista ${ }^{4}$ duda constantemente de los fundamentos de todo vocabulario, incluido el propio, descree de su herencia y de las tradiciones que la conformaron, se aparta de lo que damos normalmente por sentado y se dedica a la creación de formas alternativas de ser y estar en el mundo guiada por el deseo de perfección y sublimidad (1989, 73 ss.).

En la esfera pública la personalidad actuante es la de la liberal etnocéntrica. Partidaria de un liberalismo maduro y desdivinizado, sabe de la futilidad de los intentos de basar su alternativa política en la razón, la ciencia, el sujeto trascendental, el hombre nuevo desalienado o cualquier otro recurso teórico. Sabe, igualmente, que el liberalismo etnocéntrico surge únicamente a la sombra de nuestra cultura y nuestra comunidad. Su única contestación a la pregunta sobre la preferibilidad de su alternativa es: ¿se le ocurre a Vd. algo mejor? ¿tiene Vd. algo que sugerir a este respecto? En otras palabras, para ella, nuestra democracia precede en importancia a cualquier reflexión sobre su pertinencia filosófica. De hecho, es una exageración típica de la modernidad pensar que es tan terriblemente importante para la política el tipo de racionalidad que se defiende en la teoría. Es perfectamente posible ocupar una posición teórica kantiana o foucaultiana y ser, al tiempo, un buen ciudadano. Es más, decir cosas absurdas es compatible con ser una buena persona $(1991 b, 192 ; 1991 c$, 135 ss., 137).

Hay, por lo demás, un objetivo perfectamente claro para este personaje: aumentar la solidaridad y evitar la crueldad y la humillación para con otros seres humanos. Siguiendo la definición de liberal ofrecida por Judith Skhlar, la liberal etnocéntrica opina que la crueldad es «lo peor que podemos hacers (the worst thing we do, 1989, $\mathrm{xv}, 146$ ). Por otro lado, siguiendo la estrategia etnocéntrica definimos como inmoral aquel tipo de acción que "nosotros" no hacemos y que si alguien hiciera repetidamente tendria como consecuencia cl que dejara de ser uno de nosotros $(1989,59)$. Así las cosas, el personaje actuante en la esfera pública encontraría una suerte de límite a sus acciones en la crueldad y la humillación producida a través de su práctica. Límite que, es importante advertirlo, no comparte con su compañera la ironista pues, como Rorty reconoce, «la redescripción a menudo humilla» y en buena medida esto es así porque ya no podemos diferenciar, como hacía la Ilustración, entre educación y reprogramación 
$(1989,90)$. Al parecer, entonces, la liberal etnocéntrica no redescribe o no lo hace acaso en los mismos términos que la ironista. ${ }^{5}$

Detengámonos un momento en algunos problemas que surgen con este personaje. Aquí, como en el tema de la verdad y la opinión, son nuestras tradiciones, nuestra cultura, nuestra forma de vida, las que constituyen el fundamento último de nuestro saber y nuestro obrar. Pero tradición, cultura y forma de vida están lejos de ser entidades homogéneas que permitan que una referencia a ellas tapone las grietas de la argumentación. En este sentido, las herramientas, los vocabularios descriptivos de los que disponemos son casi infinitos debido, entre otras razones, a la multiplicidad de interpretaciones que pueden recaer sobre aquellos conceptos que cimentan la argumentación etnocéntrica. De hecho, ino es precisamente la pluralidad interpretativa en el seno de nuestra tradición lo que constituye nuestro problema hoy? ¿No existen en su interior demasiadas convenciones rivales, demasiados valores en conflicto? ¿No nos veríamos obligados, según esto, a admitir, con Gadamer, que lo que requiere esta situación es, precisamente, phrónesis, entendida como la capacidad de distinguir y elegir lo que consideramos justo dentro de tradiciones conflictivas (véase Gadamer, 1983, 261-265)? En línea similar Bernstein señala $(1992 b, 244-245)$ la paradoja de que Rorty sea capaz de apreciar el hecho de la falta de consenso en lo que respecta a las diferentes concepciones rivales de la vida buena, mientras mantiene, ingenuamente, un esencial consenso cultural en lo que hace a las convenciones políticas sobre lo que sea la democracia.

Naturalmente, el mantenimiento de ese consenso etnocéntrico básico es importante para evitar un reproche a la pluralidad fragmentada de tradiciones rivales que podría articularse desde, por ejemplo, posiciones como la de Macintyre, a saber: la mera repetición de fórmulas excluyentes, de afirmaciones y negaciones, no constituye, en absoluto, una conversación (véase McIntyre, 1985, 222). En definitiva, el consenso etnocéntrico nos serviría de punto de apoyo a la conversación, la herramienta rortyana primordial. Sin tal consenso cualquier intento de comunicación racional degeneraría en la escisión y fragmentariedad denunciada en el texto de McIntyre.

En este sentido, Rorty afirma que lo cierto es que todos somos etnocéntricos, porque para conversar y actuar en común necesitamos compartir mínimamente con el interlocutor un conjunto de creencias etnocéntricamente definidas. En otras palabras, sólo podemos justificar nuestros valores y creencias ante aqucllos cuyos valores y creencias se solapan con los nuestros en alguna medida adecuada. De modo que no es tanto que vivamos en "mundos diferentes" a los de los amazonios o los nazis (con los que Rorty supone que nos separan tradición, cultura y valores), como que nuestra "conversión" a su punto de vista o la suya al nuestro, no será 
nunca un problema de inferencia deducida de premisas compartidas. De hecho, no existe en estos casos terreno compartido alguno del que pudiera partirse para iniciar un diálogo.

Pero aquí las cosas se complican. Si el problema del trato con la "otredad" es de "conversión", es de temer que nuestra relación con lo extraño tenga poco que ver con la conversación socrática. Entonces, el peligro en esta situación es dividir a la gente en dos tipos: aquellos que merecen nuestra atención y un cierto esfuerzo conversacional, y aquellos que no. $Y$ esto es justo lo que Richard Rorty hace: "ser etnocéntrico significa dividir a la raza humana en gente ante la cual debemos justificar nuestras creencias y los otros. El primer grupo - nuestro ethnos- comprende a todos aquellos que comparten lo suficiente de nuestras creencias como para hacer posible una conversación fructífera. En este sentido, todo el mundo es etnocéntrico cuando se implica en un debate concreto, no importa cuánta retórica "realista" produzca en sus estudios» $(1991 b, 30)$.

En este contexto, parece que la pregunta es obvia: así las cosas ¿qué impediría en el seno de su teoría una relación con lo extraño similar a la de la conquista de América en el XVI o la de África en el XIX? La respuesta de Rorty es, una vez más, circular: sólo podría impedirlo el hecho de que nuestra tradición nos ha enseñado a ver a «los otros» como capaces de enseñamos algunas nuevas verdades y hacernos por ello moralmente mejores $(1983 b, 175)$ y no, en cambio, como eventual «material» del que extraer «producto».

Pero la pregunta es todavía pertinente: ¿cómo o cuándo sucede eso? Porque lo cierto es que esta estrategia está tan centrada en el nosotros que pierde de vista en esos contactos con lo extraño la medida en que aprender implica igualmente comprensión, internalización, empatía, discusión, acción concertada, etc. En una palabra, aprender de lo otro implica la admisión de que no existe grupo alguno ante el que no estemos moral, política y metodológicamente obligados a explicar e intentar convencer de nuestras premisas y valores. De que no hay, no puede haber ni siquiera en "nuestros: términos, un mecanismo de exclusión tan duro como el propuesto. Lo cual, naturalmente, es distinto de creer que podemos "entendernos» con todos en todo momento. Pero de hecho ése ni siquiera es el caso en el seno de nuestra cultura.

\section{Cosmopolitismo y emancipación}

En opinión de Rorty, la irrupción de lo sublime en el reino de lo público, la salida del Quijote de su hacienda, ha producido desastrosas consecuencias. El prejuicio izquierdista de que debemos escapar al orden establecido, transformarlo y emanciparnos de la dominación que en él encontramos, es profundamente erróneo. $\mathrm{Y}$ en buena medida lo es porque devalúa 
el consenso intracultural necesario a la figura liberal etnocéntrica y crea la idea de que debemos abjurar de los valores de nuestra comunidad concreta para internarnos en la búsqueda de algo superior (1991b, 221 ss.; $1991 c, 164$ ss.). Si el Quijote existe, después de todo, debería quedarse en casa. O si se prefieren las palabras del caballero pragmático: «always strive to excel, but only on weekends".

Así, el problema de la emancipación y de la búsqueda de perfección deben ser expulsados de la esfera pública, si queremos proteger la libertad e igualdad del liberalismo democrático realmente existente del asalto desastroso de la ambición emancipadora. Así, al parecer, existen autores (e ideas) que mientras se mantienen en el reino de la autocreación privada son inocuos, pero que son como mínimo inútiles, y como máximo peligrosos, cuando traspasan la frontera de la esfera pública $(1989,68){ }^{6}$

De hecho, el problema de la emancipación no es relevante para la democracia: el hombre no está ni nunca estuvo encadenado, por citar ahora la metáfora rousseauniana. Éste no es un problema de liberar o emancipar nada. De lo que se trata es de: 1) elaborar mecanismos de inclusión en el "nosotros" etnocéntrico que incluya el máximo número de "extraños" posible; y 2) refinar las fórmulas contingentes de justicia pública y cornunicación en el campo de juego de nuestra cultura. Estas tareas las encomienda Rorty a dos tipos de agentes: los «agentes del amor y la diversidad" que llaman nuestra atención sobre los tipos heterogéneos de personas que por alguna razón han sido dejadas fuera de la definición del nosotros; y los kagentes de la justicia y la universalidad" que cuidarían de prevenir la existencia de discriminación alguna (en nuestros términos) respecto de aquellos que ya forman parte del nosotros (1991b, $206 \mathrm{ss}$.).

Así, la liberal etnocéntrica buscaría una continua expansión del nosotros a través de narrativas más y más cosmopolitas. Si, según ella, no existe una naturaleza humana "previa" capaz de unirnos en un "nosotros" planetario, no es menos cierto que tal naturaleza humana es creada paso a paso a través de síntesis cada vez más amplias, más ricas y umás dolorosas" de valores opuestos $(1991 b, 213)$. Si finalmente llegamos a ser un grupo humano homogéneo (o lo suficientemente homogéneo) será como consecuencia de la continua expansión cosmopolita. En esta tarea la reformista-liberal-etnocéntrica-cosmopolita (pues todas esas cosas hay que ser al tiempo) ofrece nuevos vocabularios a su comunidad como alternativas de comprensión y autocomprensión, mientras sugiere que merece la pena pensar de otra manera, actuar de otra manera, ser de otra manera (1989, 9 ss., etc.).

Asi, el acomodo al statu quo que el etnocentrismo puede comportar se ve equilibrado por la llamada al cosmopolitismo y al refinamiento de los métodos para tratar con lo extran̆o. Sin embargo, para que esta operación sea posible se han de dar ciertas condiciones. 
Primero, que nuestra cultura nos provea de tensiones internas que nos hagan volver la mirada hacia las nuevas iniciativas en la esperanza de superar esas tensiones. La fidelidad a la autoimagen social, por ejemplo, resulta un buen paradigma de lo dicho: la protesta en nombre de lo que la comunidad dice ser y la capacidad de hacerla enfrentarse con aquello que realmente está siendo en un asunto particular (por ejemplo, "decís ser tolerantes, sin embargo mirad lo que estáis haciendo aquí o allá»). En realidad nuestra cultura nos provee de tales tensiones en la medida en que se precia de ser una cultura no monolítica, tolerante con la pluralidad de subculturas y decidida a escuchar lo que otras culturas tienen que decir $(1989,60 ; 1991 b, 13-14)$.

Segundo, se requiere igualmente de imaginación que permita a las personas describir y atender a descripciones realizadas en términos no habituales y escapar así de los "vocabularios congelados» heredados del pasado y cuya función conșiste prioritariamente en justificar el presente estado de cosas y sus instituciones (1991c, 186-189). La promoción de la imaginación debería, por tanto, equilibrar las rutinas socializadoras establecidas y necesarias para la reproducción de nuestras democracias realmente existentes. ${ }^{7}$

En tercer lugar se requeriría igualmente de una virtud escasamente esperable en el contexto de vida de la apacible liberal etnocéntrica: se requeriría, en efecto, de valentía. Valentía porque los argumentos que podemos dar en favor de las alternativas imaginativo-reformistas serían siempre del tipo: «intentémoslo, nada más parece funcionar». En este sentido, no podemos evitar internarnos en experimentaciones sociales arriesgadas puesto que nunca tenemos seguridad o fundamentación racional alguna que viniera en nuestra ayuda (1991c, 190-191). Sin embargo, o precisamente por ello, nuestra experimentación debe ser "pequeña» (quizá fuera mejor decir: modesta), sin pretender ofrecer alternativas globales del tipo al que la modernidad nos tenía acostumbrados (1992a).

No obstante, ¿estamos aquí tan lejos de una visión politica que trate menos displicentemente el problema del dominio y de la emancipación del dominio? ¿Es cierto que la búsqueda de lo sublime es «completamente irrelevante" en este momento (sobre todo si es definida, como Rorty hace siguiendo ahora a Lyotard, como el intento de hacer presente que lo nopresente existe)?

Es posible que una cierta variedad de lo sublime y de su correlativa oposición al dominio se nos cuele tanto por el lado de la imaginación y la valentía experimental como por el de la tendencia a la superación de tensiones que representan condiciones injustas e insoportables. Después de todo por vías muy similares lo sublime y la búsqueda de lo distinto se coló en algunos planteamientos modernos sobre el tema. 


\section{Algunos problemas (politicos) pendientes}

\section{Lo público y lo privado}

El Quijote es la imagen del mundo muerto (y por ello risible, y por ello triste) de la caballería y la justicia. La crueldad de Cervantes consistió en hacerle despertar de su «locura» en su lecho de muerte. Pero la crueldad de Rorty le hace vivir en su hacienda sublimando su impulso humanitario y reconvirtiéndolo en ironía privada. No menos sorprendido debe andar Sancho convertido no sólo en gobernador de una ínsula, sino imposibilitado para volver al calor de lo privado. Claro que Sancho no es un liberal más que en la medida en que sus ambiciones son estrechas, egoístas, realistas y razonables. Claro que Quijano sólo es ironista en la medida en que persigue lo sublime, en la medida en que se convierte en Don Quijote. Las ambiciones de Sancho son privadas y plagadas de ironía y, a ratos, de autoironía. Las del Quijote, públicas, guiadas por la solidaridad y la justicia. Lo que hace a este último algo cercano a un fanático no son sus obsesiones privadas, sino sus deseos de justicia. Lo que hace al primero un personaje entrañable y torpe no es su conocimiento de lo público, sino su manejo irónico, estratégico y kadecuado» de las convenciones que regulan interacciones privadas. Los papeles parecen cambiados.

$¿$ Ha sido poco afortunada la metáfora cervantina para ilustrar la historia del caballero pragmático? Quizá. Pero también es posible que lo que ocurra es que Quijote y Sancho no hagan más que poner de manifiesto las dificultades de la escisión propuesta por Rorty.

Nancy Fraser (1989, 306 ss.) distingue en Rorty tres posiciones distintas para tratar de armonizar la escisión entre privado y público. La primera, la estrategia de la "mano invisible», presupone una esencial armonía entre ironía privada y política reformista, entre los intereses del poeta fuerte y los de los humildes y oprimidos, entre el individuo aislado que persigue su placer estético y la solidaridad con aquellos que sufren. En un segundo momento, el propio Rorty desmonta esta primera estrategia (un tanto ingenua), concediendo que las actividades de la ironista son en buena medida reactivas y pueden llegar a ser crueles para con aquellos a los que busca redescribir. En este caso, ambos elementos entran en tensión, pues mientras el lado público y pragmático se inclina hacia la identificación con la propia comunidad, el lado privado y romántico desata el elitismo, la subversión y, eventualmente, la crueldad para con otros. Es entonces cuando aparece la tercera estrategia. En ella se afirma que, puesto que cuando la íronía se convierte en pública puede dañar, debemos circunscribirla al mundo privado para evitar sus consecuencias indeseables. Fraser señala entonces, con ironía, que Rorty ha encontrado una vía para neutralizar las implicaciones políticas no-liberales del pensamiento radical del 
poeta fuerte: negar que el pensamiento radical tenga implicación política alguna.

Perro no es sólo que esta posición parezca bastante difícil de sostener. Es que presupone que la escisión privado-público puede funcionar suavemente como asiento de una política de solidaridad y cuidado de los otros cuando es precisamente esa escisión la que se ha convertido en opresiva para ciertos grupos en nuestras sociedades (véase, por ejemplo, Benhabib, 1989, 154). Los problemas de la situación de las mujeres, la homosexualidad, el aborto, la violencia doméstica, la manipulación psíquica en sectas religiosas o de otro tipo, la pornografía, el consumo de drogas ilegales, los valores en la abra de arte, la contaminación ambiental irreversible que un propietario ejerza sobre su propiedad, etc. ¿son asuntos públicos o privados? De hecho, casi todas las materias de aguda controversia política hoy se entremezclan con el problema de los límites entre lo público y lo privado. De este modo parece difícil fundamentar sobre un asunto tan problemático una escisión tan fuerte como la propuesta por el caballero pragmático.

Y esto por no hablar de otro aspecto de la cuestión, a saber: ¿cómo resulta posible combinar ambos elementos, la ironía privada y la solidaridad pública, en una sola persona? ¿de qué manera la ironista puede ser redescriptiva e irónica en lo privado pero no en lo público? ¿cómo el narcisismo estético podrá asumir responsabilidades públicas al cruzar una línea imaginaria? ${ }^{3} \mathrm{Y}$, después de todo, ¿escribir un libro es una actividad pública o privada? ¿el marqués de Sade hacía propuestas públicas o privadas?

Por lo demás, esta escisión no aprecia suficientemente el impacto transformador que las prácticas políticas pueden tener en la propia constitución del individuo. Rorty en este punto parece asumir una visión privatizada, no participativa y aislada de los individuos, profundamente arraigada en la tradición liberal, mientras descarta la visión de un individuo interactivo propio de visiones de democracia "fuerte" o expansiva" (véase, por ejemplo, Barber, 1984; Warren, 1992). En este sentido, Sheldom S. Wolin (1990, 24-25) parece tener razón cuando afirma que la exaltación rortyana de lo privado tiene implicaciones antidemocráticas.

De hecho, hay un cierto coqueteo con el elitismo por parte de Rorty. Así, según se nos dice (1989, 87 ss.), en su utopía liberal los intelectuales serán ironistas, pero el resto de la sociedad deberá conformarse a un modelo de nominalismo e historicismo guiado por el sentido común. Si todos fueran ironistas el lazo social no podría pervivir. Por tanto, la ironía juega un papel bastante restringido y confinado a la labor de unos cuantos «elegidos».

No la menor de las razones por las que Rorty se ve obligado a ese giro elitista es su propia consideración de la crueldad que la redescripción ironista genera y cuya exclusión del reino de lo público es el objetivo de la reformista solidaria. 
"La redescripción [de la ironista], escribe Rorty, a menudo humilla" $(1989,90)$. El deseo de la liberal es, sin embargo, «evitar la crueldad y el dolor» $(1989,65)$. Sin embargo, es posible distinguir entre lo público y lo privado y eso permite a una sola persona ser al tiempo ironista y liberal etnocéntrica $(1989,198)$.

Pero, el caballero pragmático también escribe: 1) «cualquier cosa puede hacerse parecer buena o mala a través de la redescripción» $(1989,73)$, y 2) no hay forma de trazar una línea que divida claramente "persuasión y fuerza» $(1989,48)$.

Este conjunto de citas ponen de manifiesto, creo, la tremenda tensión interna del constructo rortyano. Aunque para el caballero pragmático la prioridad dada a la ironía o a la solidaridad solo puede ser decidida a través de una deliberación concreta $(1989,194)$, resulta difícil no advertir los problemas de tal deliberación.?

Por un lado, si cualquier cosa puede ser redescrita alternativamente, ¿no puede la crueldad redescribirse en términos no ligados al dolor y la humillación, y de esta forma dejar de constituir un límite a la acción pública de la liberal-etnocéntrica?, ¿no podría suceder que, pese a que el dolor es "no-linguíístico" $(1989,94)$, sea susceptible de redescripción alternativa y en consecuencia pueda ser transformado en "bueno", "necesario", "tolerable», etc?

Por otro lado, si no hay forma de especificar cuál sería la «fuerza del mejor argumento» (Habermas) dentro del proceso deliberativo, dado que no hay manera de separar nítidamente la fuerza o la manipulación de la persuasión racional, entonces, ¿qué sentido tiene hablar de deliberación (racional) en absoluto? Pero de nuevo la respuesta rortyana podría ser aquí circular: persuasión racional para nosotros, discriminación de mejores o peores argumentos según nosotros, etc. El «nosotros» tapona toda grieta de su argumentación. Y eso tiene sus riesgos. Quizá no el menos importante haya sido expuesto con claridad por C.B. Guignon $(1982,366)$ cuando escribe: "Al meramente aftrmar los valores democráticos, Rorty corre el riesgo de hundirse en el mismo dogmatismo que quiere combatir». Pero hay más problemas asociados a esta estrategia. Porque, al fin y al cabo, ¿quiénes somos nosotros?

\section{Nosotros}

Hay un segundo conjunto de problemas que trataremos de resumir alrededor del uso del pronombre eje de la estrategia etnocéntrica rortyana: nosotros.

El nosotros etnocéntricamente definido ocupa en la estrategia rortyana el lugar de un punto arquimédico: sirve a la definición de mínimos conversacionales, sirve para contestar a la pregunta cante quiénes debe- 
mos justificarnos?, sirve a las delimitaciones racional-irracional o justo-injusto (racional para nosotros, justo para nosotros), sirve al establecimiento de límites políticos definitorios de la crueldad (cruel para nosotros), etc. No obstante ¿quiénes somos nosotros?

Un repaso no exhaustivo de los escritos de Rorty ofrece las siguientes respuestas a esa pregunta: 1) nosotros intelectuales liberales de Occidente; 2) nosotros habitantes de las ricas democracias del Atlántico Norte; 3) nosotros liberales burgueses postmodernos; 4) nosotros intelectuales izquierdistas americanos; 5) nosotros socialdemócratas; 6) nosotros socialistas; 7) nosotros liberales socialdem6cratas, tristes y alejandrinos; 8) nosotros liberales trágicos; $\mathrm{y}$, desde luego, etcétera.

Con su tanto de sorna Richard J. Bernstein supone que Rorty quizá esté queriendo decir en el fondo algo como esto: nosotros, esto es, todos aquellos que están de acuerdo conmigo.

El insuficiente tratamiento rortyano del nosotros es quizá uno de los puntos más débiles de su pragmatismo. Su ya aludida ingenuidad al ver en el nosotros el producto de una sola tradición, aproblematiza precisamente las decisiones más trágicas a las que nos vemos forzados en el seno de nuestra cultura occidental. Acaso por ello el epíteto que Unger le dedica, y él recoge gustoso, de liberal trágico, no sea en este aspecto adecuado. ${ }^{10}$

Por otro lado, su definición de "lo otron no deja de ser interesada. Los nazis y los amazonios suelen ejemplificar en sus escritos esta categoría junto a Ignacio de Loyola y otros. Pero claro, que los nazis sean «lo otro" resulta muy conveniente (aunque escasamente convincente): así se ahorra uno tener que argumentar en torno a cómo es posible que nuestra cultura liberal occidental esté emparentada con fenómenos como los campos de exterminio por algo más que meros accidentes. Pero ni los análisis de T.W. Adomo y M. Horkheimer (1971), o el de H. Arendt (1974), o el más reciente de Z. Baumann (1989), parecen convencer al caballero pragmático de la necesidad de explorar esta dirección.

Del mismo modo, si admitimos la pluralidad de tradiciones rivales que conforman nuestra cultura, quizá fuera bueno recordar algo que un discípulo, algo díscolo, del caballero pragmático afirmaba recientemente: "no podemos hablar con seriedad de individualidad y democracia sin reconocer que hay todo un grupo de personas [en nuestras propias sociedades] para las cuales estos términos carecen hoy de sentido* (Cornell West, citado en Boynton, 1991, 40). O sea, que, incluso en nuestro mundo occidental, todavía hay un buen número de excluidos de aquellas instituciones y valores básicos que nos definen y para los cuales es difícil pensar, con Rorty, que hemos llegado a una situación en la cual ya poseemos tanto las herramientas conceptuales como las instituciones (democráticas) para abordar cualquier cambio necesario (1989, 63; 1991b, 21 ss., 197 ss.; etc.).

Este parece un buen sitio para aludir a una polémica sobre el nos- 
otros producida entre Michel Foucault y Richard Rorty. Frente al reproche de este último de que el primero no hacía referencia alguna a un nosotros conformador de las prácticas por él recomendadas, el filósofo francés respondía que precisamente de lo que se trataba formulando ciertas cuestiones, descripciones y preguntas era de hacer posible la formación de un "futuro nosotros" (Foucault, 1984, 385). La mediación de Bernstein en la polémica es, en parte, favorable a Foucault $(1992 a, 247 \mathrm{ss}$ ), pero la contestación de Rorty tiene también su peso polémico: sólo podemos hacer propuestas políticas radicales manteniendo fijo algún tipo de background compuesto de descripciones, asunciones y esperanzas compartidas (1987, 575). Aun concediendo la razón a Rorty en este último aspecto, no es menos cierto que el peso del reproche foucaultiano no se circunscribe al problema de si hay o no un background previo, sino, en mi opinión, a la deseabilidad y posibilidad de creación de un nosotros radicalmente distinto. $Y$, en este punto, es patente que, temiendo la irrupción de Don Quijote en la esfera pública, la contestación de Rorty es un rotundo no a ese «empujar hacia afuera» que la tensión de un futuro nosotros aconseja. Llegamos así al problema del cambio político.

\section{Politica reformista}

Al comienzo de su artículo "Trostky and the Wild Orchids" el caballero pragmático escribía: «Si hay algo de verdad en la idea de que la mejor posición intelectual es aquella que es atacada con igual vigor por la izquierda y la derecha políticas, entonces estoy en buena forma». En otro lugar $(1987,575)$, este hijo de familia trotskista se felicita en todo caso de haber recibido críticas de derecha pues, de otro modo, hubiera temido haberse convertido en un «neoconservador durante el sueño, como Gregorio Samsa». En su opinión, lo que está ocurriendo es que sus concepciones filosóficas ofenden a la derecha, al ser interpretadas como demasiado cercanas al nihilismo, puesto que cercenan las referencias a la razón, la objetividad, etc., de nuestros valores más queridos. Lo que ofende a la izquierda son, sin embargo, ciertas preferencias políticas tachadas de encontrarse demasiado cerca de la comunidad etnocéntrica urealmente existente» (Rorty, 1993, 141). En lo que sigue nos centraremos en este segundo problema.

El caballero pragmático es sensible a las injusticias y el dolor de nuestro mundo. El caballero pragmático es un reformista que opina que la ciencia de la política es una ciencia experimental, y que debemos abandonar las grandes teorías al respecto (o, al menos, esperar a que se formulen nuevas teorías con mayor poder explicativo que las existentes). Las únicas fórmulas de cambio que posecmos son "crudely experimental " y debemos conformarnos con ser concretos, banales y pragmáticos cuando hablamos 
de política real. Gran parte de las esperanzas sociales tienen poco que ver con las grandes palabras, y mucho con acciones concretas y limitadas que no requieren de referencia alguna a la historia, la naturaleza de la modernidad o la dialéctica de la ilustración (Rorty, 1992a, 3 ss.).

Sin embạrgo, esta visión debe distinguirse de la que sostienen ciertos radicales para los cuales las democracias occidentales esconden defectos estructurales probablemente irreparables. Para Rorty las democracias no son más que bricolages experimentales y prometedores $(1987,568)$ y «nada hay de malo en ellas» $(1991 b, 34)$. Precisamente porque no comparten esa visión es por lo que teóricos como Jürgen Habermas se fatigan en amplios análisis sobre el significado político de ciertos fenómenos e intentan vincularlos con algo así como el poder transformador de la razón. Esto irrita un tanto al caballero pragmático porque supone una continua crítica centrada. en nuestras democracias y - lo que es todavía más grave en el caso de Foucault, 1991b, 16-, desconsidera la atención necesaria que debe prestarse a los escenarios viables para su reforma $(1987,570)$.

Pero aquí hay dos problemas. El primero que el que una altemativa sea excesivamente general, teórica, utópica o inviable, dependerá, al menos en parte, del vocabulario en que sea expresada. O sea, que la capacidad redescriptiva de los vocabularios ya aludida con anterioridad debería aplicarse igualmente a este problema, que por cierto es viejo. Así por ejemplo, ya Karl Mannheim advertía que desde la "perspectiva» de los ideólogos toda propuesta de transformación era calificada de utópica, mientras que para los que ocupaban una "perspectiva» utópica la viabilidad de sus propuestas estaba vinculada, precisamente, a la transformación de la situación presente.

El segundo problema se refiere a la magnitud del cambio. Desde una perspectiva como la defendida por el caballero pragmático sería de esperar que la transformación concreta que se recomienda se vinculara con temas puntuales y de esfera de acción limitada. Sin embargo, eso no es así. Lo que sigue vivo del marxismo y en el cristianismo, según Rorty, es, nada menos, que la indignación ante el hecho de que la ambición y la avaricia desbanquen a la solidaridad, de que los ciudadanos ricos del primer mundo no quieran compartir a través de los impuestos algo de su riqueza con los que viven en peores condiciones que ellos, o ayudar a las economías del Tercer Mundo por idénticas razones, etc. Todo esto produce «indignación" al caballero pragmático que cree que ante ese problema todo lo que podemos decir es algo tan banal como "la gente debería ser más amable y generosa, y menos egoísta", sin que podamos soñar con algo así como un "hombre nuevo", puesto que por el momento las virtudes públicas seguirán siendo parasitarias de los vicios privados (1992a, 14 ss.).

Pero ¿cómo se supone que podemos avanzar en una transformación tan radical como la que aquella "banalidad" sobre ser moralmente mejores implicaría? ¿desde qué presupuestos medir una transformación que 
intente incrementar las virtudes civicas si, al tiempo, admitimos que lo mejor que podemos hacer hoy es seguir dando la razón a Mandeville y mantener la ingenua e interesada visión de que lo que hace funcionar a la democracia es, precisamente, la existencia de aquellos vicios privados (avaricia, egoísmo, etc.)? ¿de qué modo asumir ciertas transformaciones estructurales que se harían necesarias para abordar el cambio hacia la solidaridad en nuestras poblaciones occidentales, cuando al tiempo se señala que nuestras democracias no tienen defectos estructurales relevantes?

El caballero pragmático pasa de un relato en el que habla de democracia como ideal normativo a otro que se refiere a la democracia realmente existente sin que pueda advertirse que está cruzando una frontera (y una frontera importante). De esta forma escamotea el problema de si nuestras formas de vida son o no intrínsecamente injustas y funcionan sistemáticamente en perjuicio de ciertos grupos $\mathrm{y}$ colectivos (McCarthy, 1992, 35). Del mismo modo, no contestar directamente a este interrogante (o hacerlo suponiendo que la respuesta es no) le permite evadir lo que es el corazón del problema de la transformación política hoy.

$$
\text { *** }
$$

Ya hemos dicho que Roberto Mangabeira Unger, ese filósofo brasileño, como lo califica Rorty $(1988,79)$, coloca a nuestro caballero pragmático entre los liberales trágicos. Hay parte de verdad en ello porque Richard Rorty nunca ha dejado de sentir el impulso de Don Quijote. Frente a la autocomplaciencia de buena parte del liberalismo contemporáneo, ha roto más de una lanza oponiéndose a esa autoseguridad e intentando determinar si, pese a todo, es posible un liberalismo con rostro humano: menos seguro de sí, menos dispuesto a echar mano de la naturaleza humana para justificarse, menos embarcado en la fundamentación incontrovertible de los valores a él asociados, etc. Su aspecto trágico proviene de una fuerte reivindicación de ciertas creencias vinculadas con aquel liberalismo que critica y al que trata de hacer humano. Quizá, incluso, demasiado humano para algunos paladares.

No obstante, para otros pesa más que este aspecto de su proyecto la sensación de gratuidad y facilidad con las que funcionan otras de sus explicaciones. Vocabularios que se oponen a vocabularios, redescripciones que se oponen a redescripciones, aquí no hay guerras, ni violencia, ni dominación, ni imposiciones intolerables, hay simplemente juegos de lenguaje en escenarios alternativos. La democracia realmente existente no tiene defectos estructurales, etc. Estamos, quizá, ante el radicalismo fácil (Wolin) de una utopía liberal exenta de tragedia (Bernstein) y sin elecciones trágicas. Aquí nuestro caballero no es un liberal trágico, sino cómodo y hasta cierto punto reconfortante. 
Si finalmente el Quijote" sale de su hacienda y mide sus fuerzas en empresas verdaderamente grandes, no lo hace en el seco y famélico Rocinante, aquel que en su conversación con otro caballo famoso, Babieca, contestara a la observación: "Metafísico estáis», con un contundente: "Es que no comon.12 Parece que el caballero pragmático prefiere salir en el burro de Sancho Panza, menos interesante literariamente (el burro, no Sancho) y menos trágico en su aspecto. Aquellos (la derecha) que al ver su figura reconocen en ella al ingenioso hidalgo, sin pararse en mientes de que monta un burro, sienten todos los peligros que su espíritu trae a lo establecido. Aquellos (la izquierda) que al acercarse a él ven en primer plano su montura, desconfían de que caballero tan famoso pueda finalmente acometer empresas grandes en tan endeble compañía.

\section{BIBLIOGRAFIA}

ADorno, T.W. y HorkHemer, M. (1971): Dialéctica del lltuminisno, Buenos Aires, Sur.

ARENDT, H. (1974): Los origenes del totalitarismo, Madrid, Taurus.

Barber, B. (1984): Strong Democracy: Participatory Politics for a New Age, Los Ángeles, University of California Press.

Bauman, Z. (1989): Modernity and the Holocaust, Oxford, Polity Press.

BENHABIB, S. (1989): «Liberal Dialogue vs Critical Theory of Discursive Legitimation», en R.L. Rosenblum (ed.), Liberalism and the Moral Life, Cambridge, MA, Harvard University Press.

BERnSTEn, R.J. (1983): Beyond Objectivism and Relativism, Oxford, Basil Blackwell.

- (1992a): “Rorty's Liberal Utopia», en MA, The New Constelation, Cambridge. The MIT Pres.

- (1992b): "One Step Fonward, Two Steps Backward: Rorty on Liberal Democracy and Phylosophy», en The New Constelation, Cambridge, MA, The MTT Press.

Bornron, R.S. (1991); «Princentor's Public Intelectual», The New York Times Magazine (15 de septiembre).

Foucaurt, M. (1984): The Foucault Reader, en P. Rabinow (ed.), Nueva York, Pantheon Books.

FRASER, N. (1989): «Solidarity and Singularity? Richard Rorty between Romanticism and Technocracy», en Unruly Practices, Cambridge, Polity Press.

GaDAMER, H.G. (1983): "Ä Letter by Professor Hans George Gadamer" en R.J. Bernstein, Beyond Objectivism and Relativistn, Oxford, Basil Blackwell.

GDDEks, A. (1985): aReason Without Revolution? Habermas' Theorie des kommunikativen Handelns», en R.J. Bernstein (ed.), Habernas and Modemity, Cambridge, Polity Press.

Guignon, C.B. (1982): "Saving the Difference: Gadamer and Rorty", en P.D. Asquith y T.H. Nickless (eds.), PSA, vol. 2, East Leasing, MI, Philosophy of Science $\Lambda$ ssociation.

KLEPP, L.S. (1990): "The Philosopher King", New York Times Magazine (2 de noviembre).

MCCARTHY, T. (1982): «The Difference that Makes a Difference: A Comment on Richard Bernstein», P.D. Asquisth y Th. Nickless (eds.), PSA, vol. 2, Philosophy of Science Association, Leasing, MI.

- (1992): Ideales e Ilusiones, Madrid, Tecnos.

MAcINTYre, A. (1985): "Moral Arguments in Social Contexts», en R. Hollinger (ed.), Hemneneutics and Praxis, Notre Dame, Universily of Notre Dame Press.

Martin, M. (1988): "Entrevista: Richard Rorty, el "liheral trágico" ", Revista de Occidente, 90 (noviembre).

NISBET, L. (1983): «Hook's Pragmatism and the Tragic Sense of Life», en P. Kurtz (cd.), Sidney Hook, Philosopher of Democracy and Htmanism, Buffalo, NY, Prometheus Books.

RorTy, R. (1982): Consequences of Pragmatism, Sussex, The Harvester Press. 
- (1983a): La Filosoffa espejo de ia naturaleza, Madrid, Cátedra.

- (1983b): «Method and Morality», en N. Haan, P. Rabinow y W.N. Sullivan (eds.), Social Sciences and Moral Inquiny, Nueva York, Columbia University Press.

- (1987); "Thugs and Theorists: A Reply to Bernstein", Political Theory, 15, 4.

- (1988): «Una esperanza social: Unger, Castoriadis y el ensueño de un futuro nacional», Revista de Occidente, 90 (noviembre).

- (1989): Contingency, Irony and Solidonty, Cambridge, Cambridge University Press.

- (1991a): *The Banality of Pragmatism and the Poetry of Justice», en M. Brint y W. Weaver (eds.), Pragmatism, Law and Society, Bouldner, San Francisco, Oxford, Westview Press.

- (1991b): Philosophical Papers I: Objectivism, Relativism and Truth, Cambridge, Cambridge University Press.

- (1991c): Philosophical Papers II: Essays on Heidegger and Othess, Cambridge, Cambridge University Press.

- (1992a): *The Intelectuals and the End of Socialism", The Yale Review، 90, 1/2 (abril).

- (1992b): "Twenty-five Years Afters, en R. Rorty (ed.), The Linguistic Tum, Chicago, The University of Chicago Press.

- (1993): "Trostsky and the Wild Orchids", Common Krowledge, 1, 3 (inviemo).

SANDEL. M. (1982): Liberalism and the Limits of Justice, Cambridge, Cambridge University Press.

Threbaut, C. (1992): "De la filosofía a la literatura: el caso de Richard Rorty», Daimon, 5, pp. 133-154.

VATtIMO, G. y Rovatn (eds.) (1983): Il pensiero debole, Milán, Feltrinelli.

Warren, M. (1992): «Democratic Theory and Self-Transformation", American Political Science Review, 86, 1 (marzo).

Woun, S. (1990): «Democracy in the Discourse of Postmodemism», Social Research, 57, 1 (primavera).

\section{NOTAS}

1. Los datos biográficos que se manejan en R. Rorty (1993) y L.S. Klepp (1990).

2. Para el caso de John Rawls esta crítica se encuentra en M. Sandel (1982), o también en R. Rorty (1991b, $197 \mathrm{ss}$ ). Para el caso de Jürgen Habermas, véase A. Giddens (1985).

3. Traduzco, a falta de una mejor solución, self a selthood por "yom, aunque naturalmente el significado de ambas expresiones no coincide con el término castellano.

4. En el vocabulario de Rorty el ironista es la ironista, mientras el metafisico es el metafisico. Igualmente, el liberal etnocéntrico es ella. Es decir, wlos buenos» son ellas. Seguiré en el texto esa convención.

5. Me pregunto si la propia distinción entre "nosotros" y "ellos" no constituye un buen ejemplo de crueldad y humillación sobre todo si se tiene en cuenta 1) la enorme diferencia de trato a la que sirve de base (véase más adelante) y 2) la definición del "ellos" como "el tipo crróneo de seres humanos" (the wrong sont of human beings, 1989, 190).

6. Estas afirmaciones aparecen en un texto en el que Rorty discute con Habermas sobre universalismo y señala cómo la crítica de éste a autores como Nietzsche, Heidegger o Derrida tiene peso en tanto a estos autores se les considera desde el punto de vista de lo público. Tan pronto como se entiende de su uso estrictamente privado se convierten en relevantes para la autocreación del ironista. La tesis que sostengo es que si admitimos esto, debemos igualmente admitir la existencia de ideas peligrosas, y que entre ellas estaria la de emancipación, que no perteneceria propiamente hablando a los autores citados, pero que es de importancia, me parece, para la práctica política de la izquierda incluso contemporáneamente. En términos măs claros, hay aquí una exclusión de lo público, tanto por la derecha como por la izquierda, que Rorty no teme terier que realizar para configurar adecuadamente su utopia liberal. 
7. Rorty comentaba recientemente, creo que sin razón, «No creo que mi propio trabajo tenga mucha utilidad para liberar nuestra imaginación. Tal privilegio sólo lo merecen hombres y mujeres de genio [...]” (M. Martin, 1988, 111). Precisamente el problema, la paradoja, consiste en que su genio redescriptivo y su imnia han iniciado un proceso publico (filosofico, filosófico y político, político) de debate en tomo a cuestiones no esotéricas ni privadas. Su escritura, su redescripción de nuestra cultura, sus dudas sobre el propio vocabulario (sobre el vocabulario liberal), su actitud ironista, etc., no se mueven en sus efectos ni en el terreno de lo privado ni en el de lo público, sino en ambos. La pregunta sería si es posible que las cosas fueran de otra manera.

8. Esta problemática recuerda la novela de Unamuno San Manuel Bueno Mártir. En ella un sacerdote con enormes dudas privadas respecto de la existencia de Dios vive dedicado a extender la doctrina cristiana porque considera esa creencia, por falsa que pudiera ser, preferible a la nada de la duda. La ironista rortyana (¿Rorty?) quisiera igualmente creer en los valores de su otro yo liberal. Le es, sin embargo, imposible hacerlo y, por ello mismo, se dedica al ejercicio de una responsabilidad pública consistente en extender y sostener aquellos valores de los que descree. La nada política (es decir, «lo otron del liberalismo democrático) no es preferible a un cierto grado de hipocresía bienintencionada. Nos encontramos ante una formulación simétricamente opuesta a la de fiat veritas et pereat mundus. Una formulación perfectamente pragmática.

9. En buena medida los problemas de la deliberación en este contexto están asociados a la incapacidad de distinguir entre buenos y malos argumentos desde una perspectiva distinta de la del pensamiento débil. Esa es la razón, por ejemplo, por la que McCarthy $(1982,372)$ critica la utilización de la metáfora del diálogo socrático por parte de Rorty (que la adscribe a su concepto de conversación). En efecto, si Sócrates está interesado en el diálogo es por su calificativo de racional, si lo está en la justicia es por su creencia en la justificación racional de la misma, etc. Son esas ideas "pasadas de moda" las que informarian el proyecto socrático. Es la ausencia de estas mismas ideas lo que dificulta el proyecto rortyano en lo que hace a la deliberación.

10. Una visión distinta de los problemas de la elección trágica en la tradición pragmática puede encontrarse en L. Nisbet (1983).

11. A lo largo de estas páginas se han hecho algunas referencias dispersas a las figuras de Don Quijote y Sancho y su posible vinculación con el caballero pragmático. Tanto la interpretación de los personajes literarios, como los paralelismos con el filosofo pragmático, son productos de lo que el propio Rorty ha definido como slectura fuerten: un comentario perverso y egocêntrico (perverse egocentric compnentary).

12. Si es la ausencia de comida lo que produce la metafisica, como parece pensar Rocinante, el caballero pragmático justificaría su cambio de montura precisamente porque el hambre (vale decir, la dominación, las injusticias estructurales, etc.) no seria ya un rasgo definitorio de nuestro mundo occidental $(o$, al menos, no sería una característica para cuya eliminación requirièramos de otra cosa que de «más de lo mismo», esto es, más democracia liberal). 